\title{
Alumina-Supported Triosmium Clusters and Ensembles: Characterization by High-Resolution Transmission Electron Microscopy
}

\author{
J. Schwank, ${ }^{*}$ L. F. Allard, $\dagger$ M. Deeba,${ }^{1}$ and B. C. Gates \\ ${ }^{*}$ Departments of Chemical Engineering and + Materials and Metallurgical Engineering, University of \\ Michigan, Ann Arbor, Michigan 48109, and Center for Catalytic Science and Technology, Department of \\ Chemical Engineering, University of Delaware, Newark, Delaware 19711
}

Received December 29, 1982; revised June 7, 1983

\begin{abstract}
Structurally defined supported osmium clusters $\left[\mathrm{HUs}_{3}(\mathrm{CO})_{10}-\mathrm{O}-\mathrm{Al}<\right\rfloor$ were prepared by the reaction of $\left[\mathrm{Os}_{3}(\mathrm{CO})_{12}\right]$ with the $-\mathrm{OH}$ groups of $\gamma-\mathrm{Al}_{2} \mathrm{O}_{3}$. The supported clusters were heated to $200^{\circ} \mathrm{C}$ in argon and then reduced in hydrogen at $400^{\circ} \mathrm{C}$, being characterized at different stages of the treatment by high-resolution transmission electron microscopy. After the sample had been heated to $200^{\circ} \mathrm{C}$, scattering centers about $6 \AA$ in diameter were evident in the micrographs, their size being consistent with the expected geometry of three-atom ensembles of Os(II) complexes formed by cluster breakup. The ensembles were remarkably stable, and even prolonged exposure of the same area to the $100 \mathrm{keV}$ electron beam caused neither disintegration nor agglomeration. After reduction of the osmium in hydrogen at $400^{\circ} \mathrm{C}$, aggregates of similar size were observed. In contrast to the ensembles of Os(II) complexes, the aggregates seemed to disintegrate slowly under the impact of the electron beam. The difference in stability of the ensembles and the reduced osmium aggregates is attributed to the difference between the strong ionic bonds in the former sample and the weaker interaction between the reduced metal and the $\mathrm{Al}_{2} \mathrm{O}_{3}$ surface.
\end{abstract}

\section{INTRODUCTION}

Supported-metal catalysts are difficult to characterize because they are nonuniform, consisting of various sizes and shapes of crystallites or aggregates of metal on a support. Molecular metal clusters have been used in attempts to prepare structurally unique supported metals, but almost all of the metal clusters decompose and undergo structural changes on the support. There are a few supported-metal clusters having unique (molecular) structures ( $l$ ). Two of the few oxide-supported clusters are the triosmium carbonyls, $\mathrm{HOs}_{3}(\mathrm{CO})_{10}-\mathrm{O}-\mathrm{M}$, where $\mathrm{M}$ is $\mathrm{Si}$ or $\mathrm{Al}$, which evidently retain their triangular metal framework structures during olefin isomerization at temperatures up to about $90^{\circ} \mathrm{C}(2,3)$; triosmium carbonyl

\footnotetext{
${ }^{1}$ Present address: Air Products and Chemicals, Inc., Allentown, Pennsylvania 18105.
}

clusters on $\mathrm{MgO}$ apparently even retain their structural integrity during catalytic $\mathrm{CO}$ hydrogenation at $300^{\circ} \mathrm{C} \mathrm{(4).}$

The oxide-supported triosmium clusters have been characterized by infrared (5-9), uv-visible (2), and Raman spectroscopies $(10)$, and by EXAFS $(5,11)$. All the spectroscopic results and the stoichiometry of the synthesis involving $\left[\mathrm{Os}_{3}(\mathrm{CO})_{12}\right]$ and surface-OH groups (5) are consistent with the presence of unique triosmium cluster carbonyls of the following structure on the oxide supports:

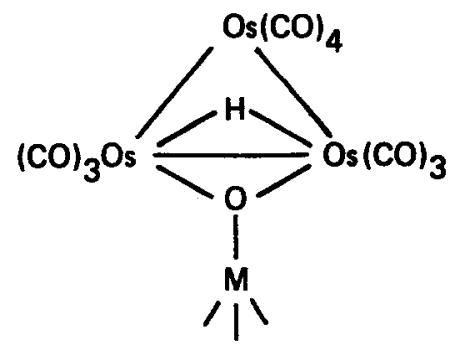


When these supported clusters are heated to about 150 to $200^{\circ} \mathrm{C}$, the infrared spectra in the carbonyl region show that the clusters break up, undergoing scission of the Os-Os bonds, formation of new Os-O bonds, and an increase in the oxidation state of Os [indicated by EXAFS (11)]. The resulting surface-bound species are mononuclear carbonyl complexes: $-\mathrm{Os}(\mathrm{II})(\mathrm{CO})_{x}$ $(x=2$ or 3$)(2-5,7-10)$. These have catalytic activities for hydrogenation and isomerization of olefins, and their activities are different from those of the supported clusters $(3,10)$. Examination of the $\gamma-\mathrm{Al}_{2} \mathrm{O}_{3}$ supported complexes by transmission electron microscopy led to the suggestion that the osmium is present on the surface in discrete three-atom ensembles, which are highly resistant to sintering (9). EXAFS results confirm the existence of these ensembles (11).

The remarkably explicit information provided by Tesche's electron micrographs of these samples (9) encouraged us to pursue a systematic microscopic investigation of the different structural forms of the supported osmium. Although it is regarded as difficult to obtain reliable, artifact-free information regarding structures $10 \AA$ or less in diameter (12), we recognize a unique opportunity with the samples derived from osmium clusters because of their structural uniformity and the excellent phase object nature of heavy elements such as osmium giving rise to good phase contrast images.

The goals of this research were to characterize $\gamma-\mathrm{Al}_{2} \mathrm{O}_{3}$-supported osmium catalysts, including those consisting of triosmium carbonyl clusters, three-atom ensembles, and larger aggregates (or crystallites) of osmium. The plan was to use high-resolution transmission electron microscopy to maximize the opportunity for structural characterizations of the osmium species. Specifically, osmium on a conventional, high-surface-area $\gamma-\mathrm{Al}_{2} \mathrm{O}_{3}$ support was prepared for microscopy with minimum sample manipulation and minimum introduc- tion of extraneous materials that could cause artifacts in the micrographs.

\section{EXPERIMENTAL}

Supported osmium catalysts were prepared by refluxing a solution of $\left[\mathrm{Os}_{3}(\mathrm{CO})_{12}\right]$ in n-octane in the presence of particles of $\gamma$ $\mathrm{Al}_{2} \mathrm{O}_{3}$ (Ketjen), as described previously (7). The surface area of the $\gamma-\mathrm{Al}_{2} \mathrm{O}_{3}$ was approximately $185 \mathrm{~m}^{2} / \mathrm{g}$. The samples were characterized by their infrared spectra in the carbonyl region, the results agreeing with those observed previously (7). The osmium content of the samples was approximately $1 \mathrm{wt} \%$.

An alumina-supported osmium sample was also prepared by conventional impregnation with aqueous $\left[\mathrm{H}_{2} \mathrm{OsCl}_{6}\right]$ followed by reduction in flowing $\mathrm{H}_{2}$ at $400^{\circ} \mathrm{C}$ for $4 \mathrm{hr}$ as described previously (7). The nominal osmium content was 4 wt $\%$.

For the characterization by transmission electron microscopy, a few milligrams of supported osmium catalyst that had been subjected to various pretreatments were sonicated in isopropanol and placed on a copper grid covered with a "holey" carbon film. After evaporation of the isopropanol, the specimens were transferred into a JEOL JEM-100CX transmission electron microscope equipped with a high-resolution top-entry goniometer stage and an ultrahigh resolution pole piece. The position of the specimen in the lens gave an objective lens current (at focus) of $1.69 \mathrm{~A}$. The spherical aberration coefficient $C_{\mathrm{s}}$ was carefully calibrated (13), so that at this specimen position in the lens, a $C_{\mathrm{s}}$ value of $0.64 \mathrm{~mm}$ was obtained. $\mathrm{A} \mathrm{LaB}_{6}$ emitter operated at 100 $\mathrm{keV}$ was used as source. The condenser aperture gave a nominal beam divergence of $1.4 \mathrm{mrad}$.

The osmium clusters and ensembles in the specimens were located at various heights along the direction of the electron beam. Photographs of clusters in the center of the field of view were typically taken at the defocus (Scherzer) position $f$ of about $-600 \AA\left(\Delta f=-1.2\left(C_{\mathrm{s}} \lambda\right)^{1 / 2}\right)$, where $\lambda$ is the 
wavelength, which is optimum for the pole piece used (14). Consequently, only objects within limited areas in a given photograph were in the focus position, while objects above or below the optimum focus plane were not at the ideal position for contrast transfer. For the interpretation of cluster size and morphology, only those sample areas experimentally set at the optimum defocus position were used. Typically, magnifications of 525,000 and 640,000 were chosen for direct recording of images. In the darkroom, these images were enlarged as much as 10 times to facilitate analysis; no special image processing or contrast enhancement procedures were used.

For imaging, sample areas dangling over the edge of the carbon film and protruding into the holes of the carbon film were selected to avoid any contribution of the support film to image contrast. Under the high- resolution conditions in the microscope, carbon shows a granular structure of considerable contrast, as evidenced in Fig. 1. At the bottom of the micrograph, where the catalyst sample overlaps the carbon film, the image is obscured to such an extent that an identification of fine structural details would be virtually impossible. At the top of the micrograph, where the sample dangles over the hole in the carbon film, the quality of the image is improved dramatically. At the outer edges of the sample where it breaks off, the thickness of the $\gamma-\mathrm{Al}_{2} \mathrm{O}_{3}$ support is reduced to a few layers. It is in these outer regions of the samples where the $\gamma-\mathrm{Al}_{2} \mathrm{O}_{3}$ contrast becomes so low that the osmium clusters and ensembles become visible as small scattering centers superimposed on the regular structural contrast of the $\gamma-\mathrm{Al}_{2} \mathrm{O}_{3}$.

The fine structure of the $\gamma-\mathrm{Al}_{2} \mathrm{O}_{3}$ was

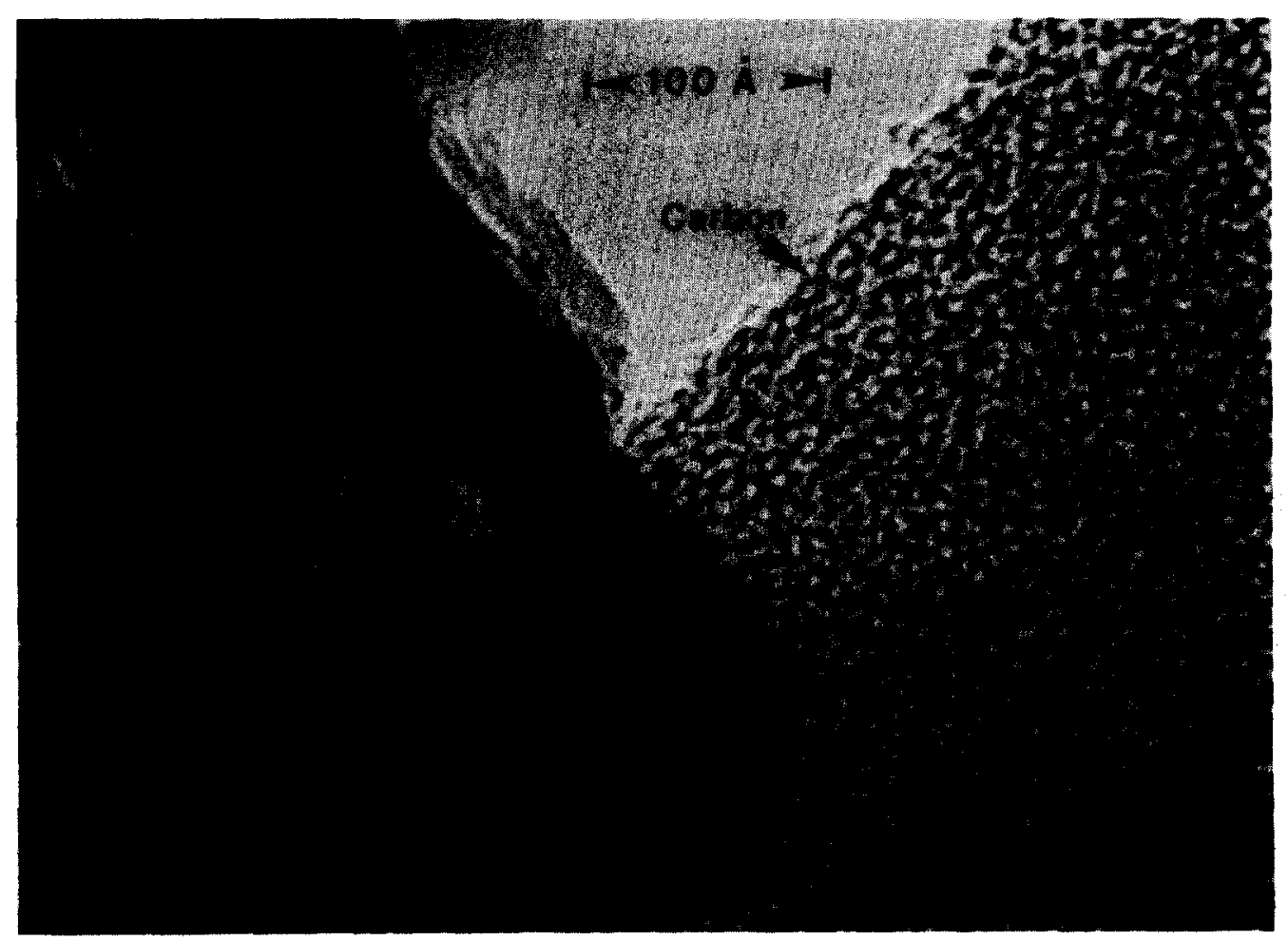

FIG. 1. Typical micrograph showing part of the holey carbon film and osmium ensembles on $\gamma-\mathrm{Al}_{2} \mathrm{O}_{3}$ at a magnification of $525,000: 1$. Some of the sample rests on top of the carbon film and part dangles over the edge, protruding into a hole. 
taken as the experimental reference for the optimum defocus condition. Microscope magnifications were carefully calibrated using lattice fringe images of partially graphitized carbon $(d=3.4 \AA$ ). Since the apparent size of scattering centers can vary as a function of focus condition $(12,13)$, it is difficult to deduce accurate particle sizes from micrographs, especially in the range $<10 \AA$.

To ensure that the results were not misinterpreted because of artifacts in sample preparation or imaging, we repeated the preparation of each sample and repeated the microscopic examinations of all the samples after an interval of 6 months. The instrumental parameters were calibrated carefully before each microscopy session. The results for any sample were essentially indistinguishable from one set of experiments to another.

In each sample, many different areasdangling over about 10 different holes in a particular carbon film-were examined. The micrographs presented in the following pages are representative generally of the samples with which they were obtained. We emphasize that no metal particles larger than those shown were observed for any of the samples.

\section{RESULTS AND DISCUSSION}

A high-resolution transmission electron micrograph of the $\gamma-\mathrm{Al}_{2} \mathrm{O}_{3}$ support (without Os) is shown in Fig. 2. There is a regular structure, which was also observed with all the osmium-containing samples. The regular structure observed in the $\gamma-\mathrm{Al}_{2} \mathrm{O}_{3}$ is probably a simple lattice fringe image effect due to the passage of diffracted beams from the $\gamma-\mathrm{Al}_{2} \mathrm{O}_{3}$ through the objective aperture. There are no additional strong scattering centers visible at the outer edge of the $\gamma$ $\mathrm{Al}_{2} \mathrm{O}_{3}$ specimen where the sample thickness is minimal; this result is important because

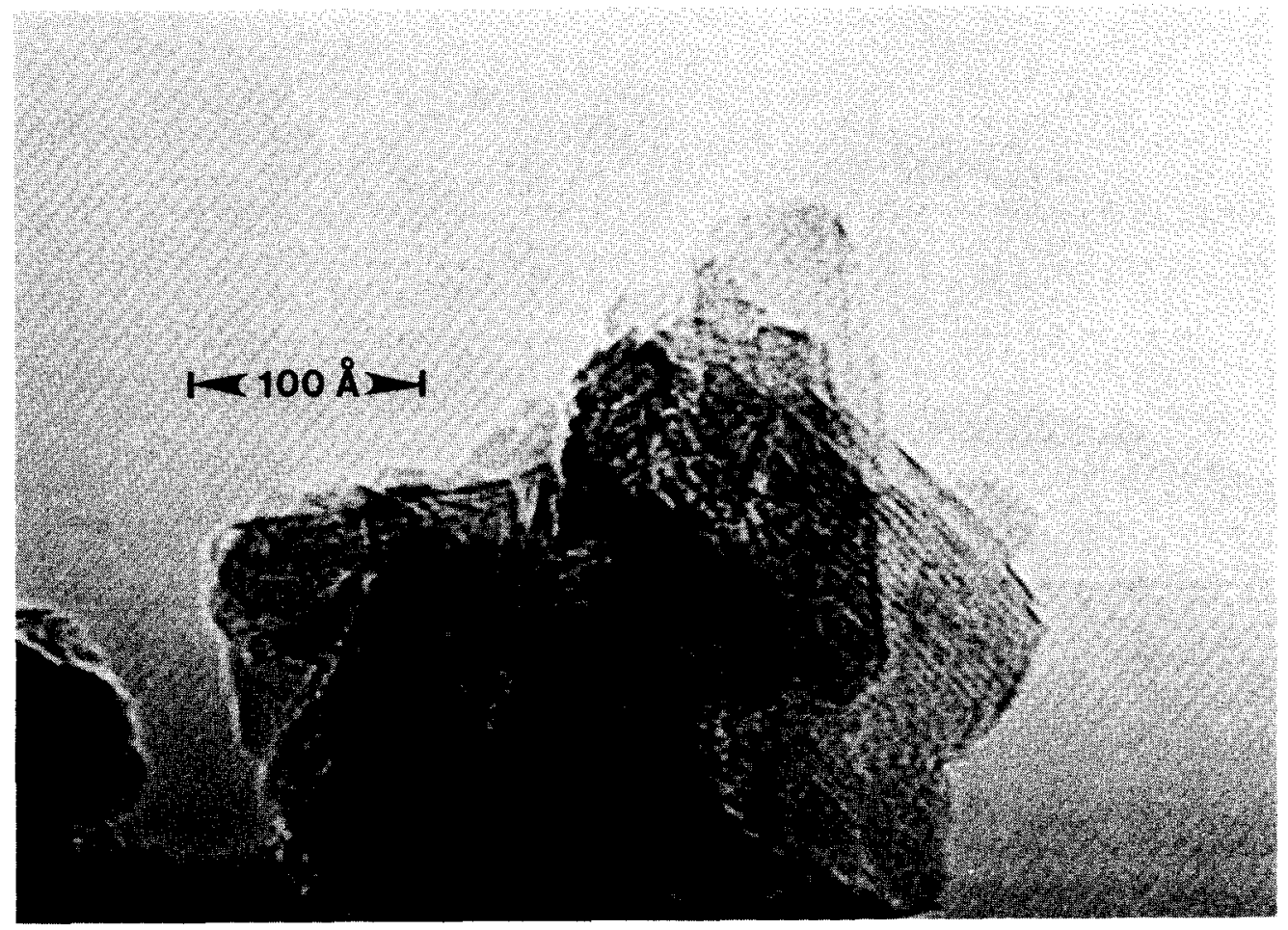

FIG. 2. Micrograph of the $\gamma-\mathrm{Al}_{2} \mathrm{O}_{3}$ support, taken at a magnification of $525,000: 1$. 
of the contrasting results observed with the osmium-containing samples mentioned in the following paragraphs.

A micrograph of the sample prepared by the reaction of $\left[\mathrm{Os}_{3}(\mathrm{CO})_{12}\right]$ with the $\gamma-\mathrm{Al}_{2} \mathrm{O}_{3}$ is shown in Fig. 3. In addition to the regular lattice structure characteristic of the $\gamma$ $\mathrm{Al}_{2} \mathrm{O}_{3}$, there are weak scattering centers of nearly uniform size. Because the contrast is low, it is difficult to estimate the sizes precisely. None of these scattering centers is larger than 5 to $10 \AA$. Since the infrared spectrum of this sample has been found to be nearly identical to the spectrum of the supported analog of the molecular cluster, $\mathrm{HOs}_{3}(\mathrm{CO})_{10}-\mathrm{O}-\mathrm{Al}<$, we infer that the scattering centers are evidence of the clusters. Some of the clusters might have undergone partial decarbonylation under the impact of the $100-\mathrm{keV}$ electron beam, leaving behind osmium species contributing to the observed scattering.
The possibility that the appearance of these scattering centers arises from localized differences in the thickness of the $\gamma$ $\mathrm{Al}_{2} \mathrm{O}_{3}$ can be ruled out. To account for the contrast observed, we would need to assume that some of the $\gamma-\mathrm{Al}_{2} \mathrm{O}_{3}$ was protruding as pillars, 5 to $10 \AA$ in diameter, on top of planar $\gamma-\mathrm{Al}_{2} \mathrm{O}_{3}$ layers. This is highly unlikely, especially in view of the results obtained with blank $\gamma-\mathrm{Al}_{2} \mathrm{O}_{3}$ (Fig. 1), for which no such scattering centers were found.

Figure 4 is an electron micrograph of a sample that had been treated in flowing argon at a temperature of $200^{\circ} \mathrm{C}$ to bring about the cluster breakup and formation of threeatom ensembles. Following the argon treatment, the sample was stored in air at room temperature. Scattering centers having an average diameter of approximately $6 \AA$ are clearly visible; we attribute these to the three-atom ensembles of osmium. The size

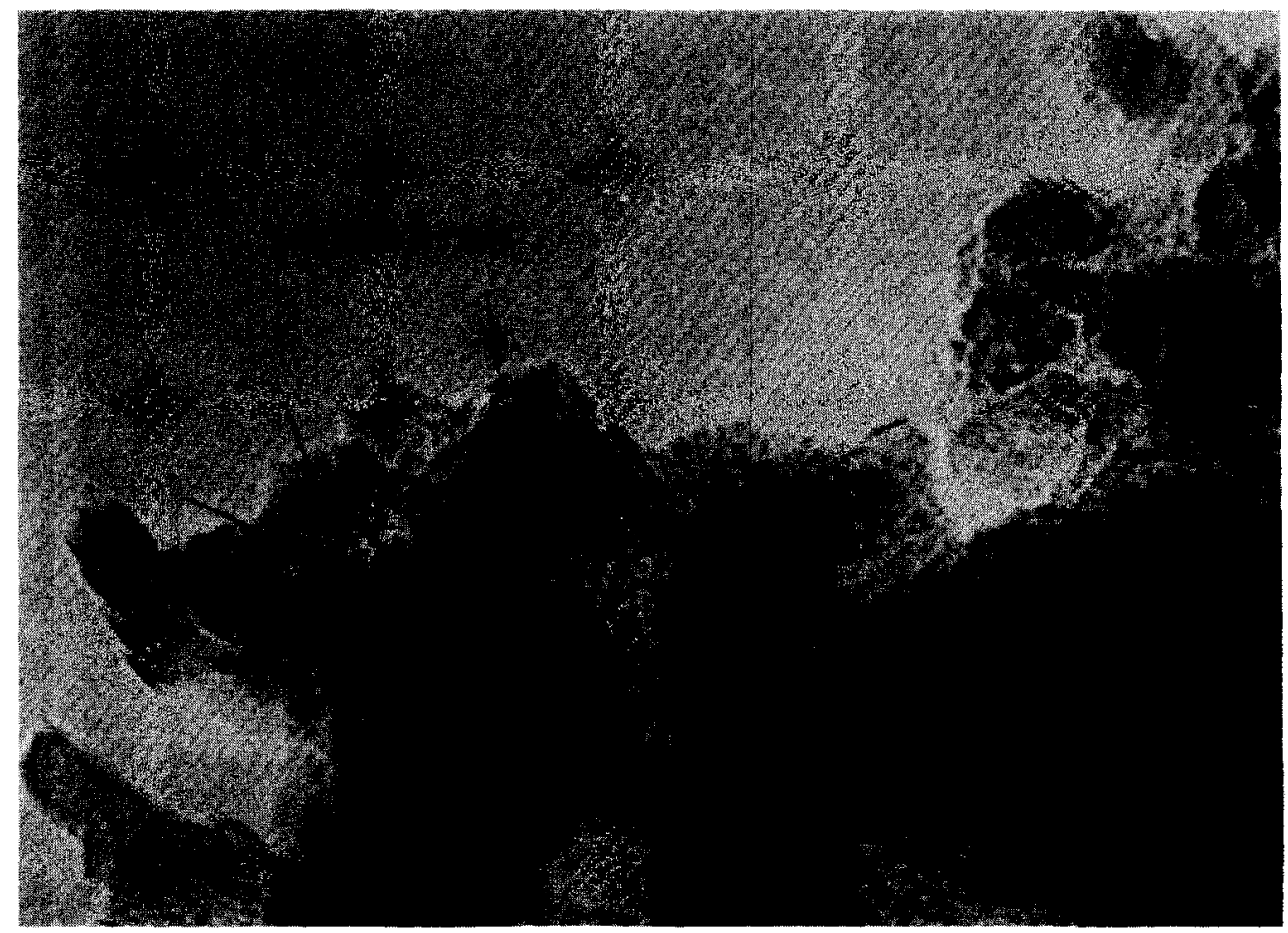

FIG. 3. Micrograph of osmium clusters on $\gamma-\mathrm{Al}_{2} \mathrm{O}_{3}$ prepared by refluxing a solution of $\left[\mathrm{Os}_{3}(\mathrm{CO})_{12}\right]$ in $\mathrm{n}$-octane in the presence of $\gamma-\mathrm{Al}_{2} \mathrm{O}_{3}$. The magnification is 525,000:1. 


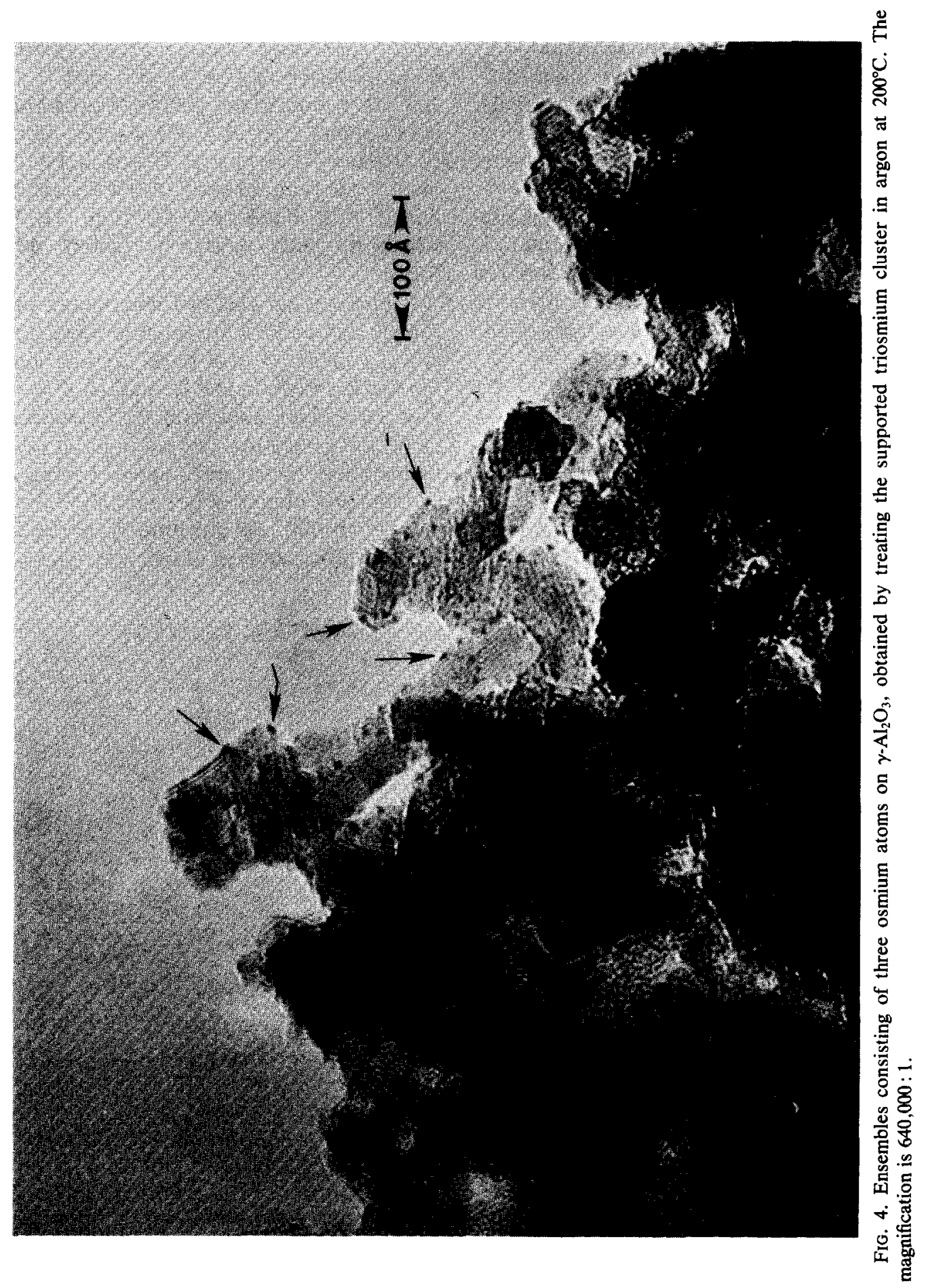



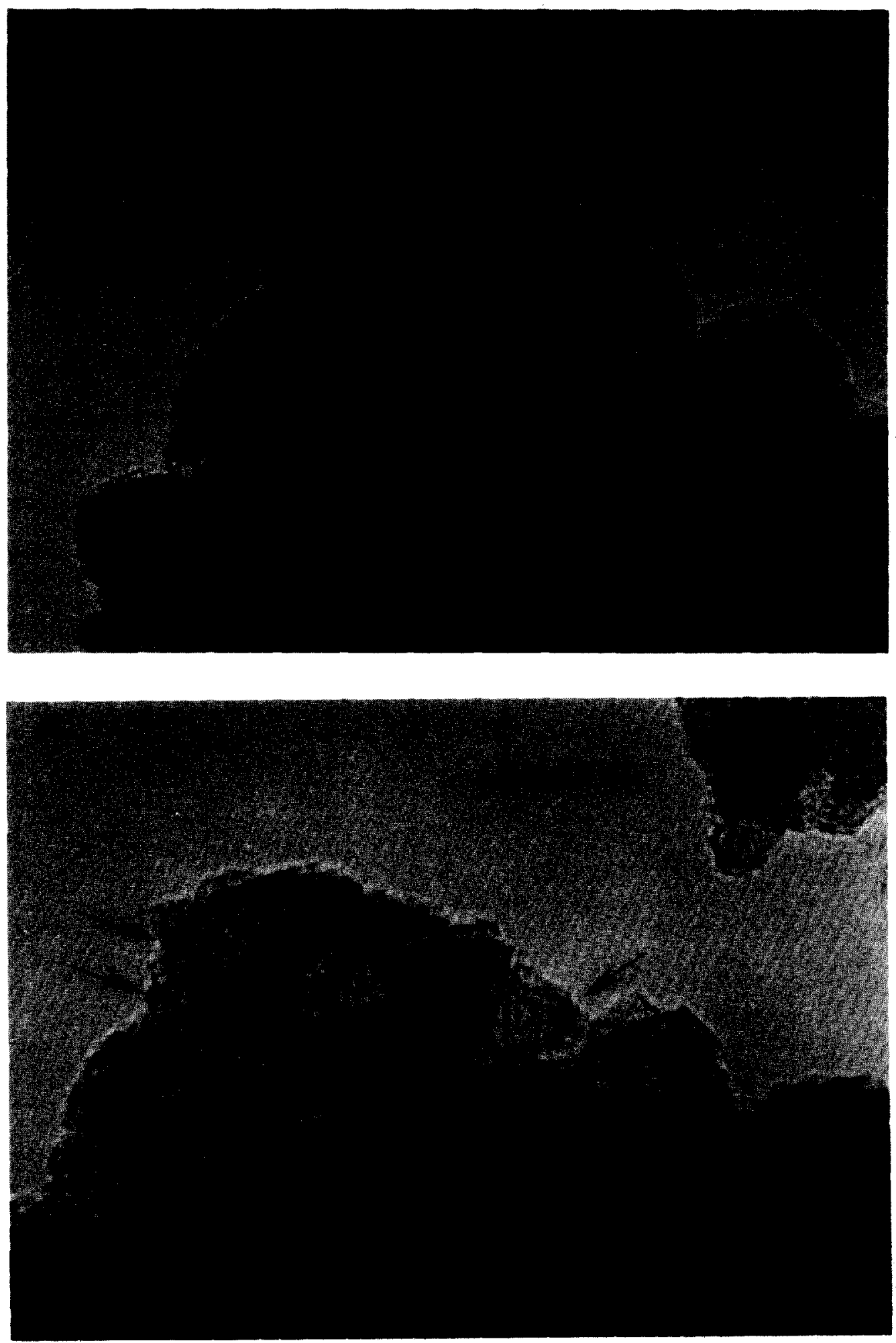

FIG. 5. Micrographs of the supported osmium ensembles taken in the sequence (A)-(B) at approximately 25 -min intervals. The same sample area was exposed to the $100-\mathrm{keV}$ electron beam for more than $25 \mathrm{~min}$. The magnification is $525,000: 1$. 
varies slightly from one ensemble to the next. Ensembles located on surfaces of $\mathrm{Al}_{2} \mathrm{O}_{3}$ layers appear to be larger in diameter than some of the ensembles positioned at the edges of the $\mathrm{Al}_{2} \mathrm{O}_{3}$ layers. We suggest that these results provide a contrast between "top" and "edge" views of the ensembles.

The supported osmium ensembles are remarkably stable. Even after prolonged exposure of the same area to the $100-\mathrm{keV}$ electron beam, no significant changes were visible, as shown in Figs. 5A and B, representing a single area photographed at 25 min intervals. We recognize, however, that we cannot exclude the possibility of some initial electron beam damage in the first few seconds of exposure of a fresh area to the beam during the period when the operator focused the image for the first photograph.

When the $\gamma-\mathrm{Al}_{2} \mathrm{O}_{3}$-supported triosmium clusters were heated to $400^{\circ} \mathrm{C}$ in $\mathrm{H}_{2}$, they underwent decarbonylation, as indicated by changes in the infrared spectra, but the precise structures of the resulting osmium species remain undetermined. An electron micrograph of the sample after reduction in $\mathrm{H}_{2}$ at $400^{\circ} \mathrm{C}$ followed by storage in air at room temperature is shown in Fig. 6A. Immediately after the first exposure to the electron beam the characteristic structure indicative of the $\gamma-\mathrm{Al}_{2} \mathrm{O}_{3}$ is clearly visible, and there are also scattering centers which are attributed to osmium aggregates ${ }^{2}<10 \AA$ in diameter. The longer the specimen was exposed to the electron beam, the fainter the scattering centers became; for example, Fig. 6B shows the same area, at the same

\footnotetext{
${ }^{2}$ We use the term "cluster" to refer to a molecule with metal-metal bonds or to a supported analog of such a molecule. The term "aggregate" refers to a smail grouping of metal atoms not necessarily having a structure like that of a molecule. Larger groupings of metal atoms are referred to as "crystallites."
}

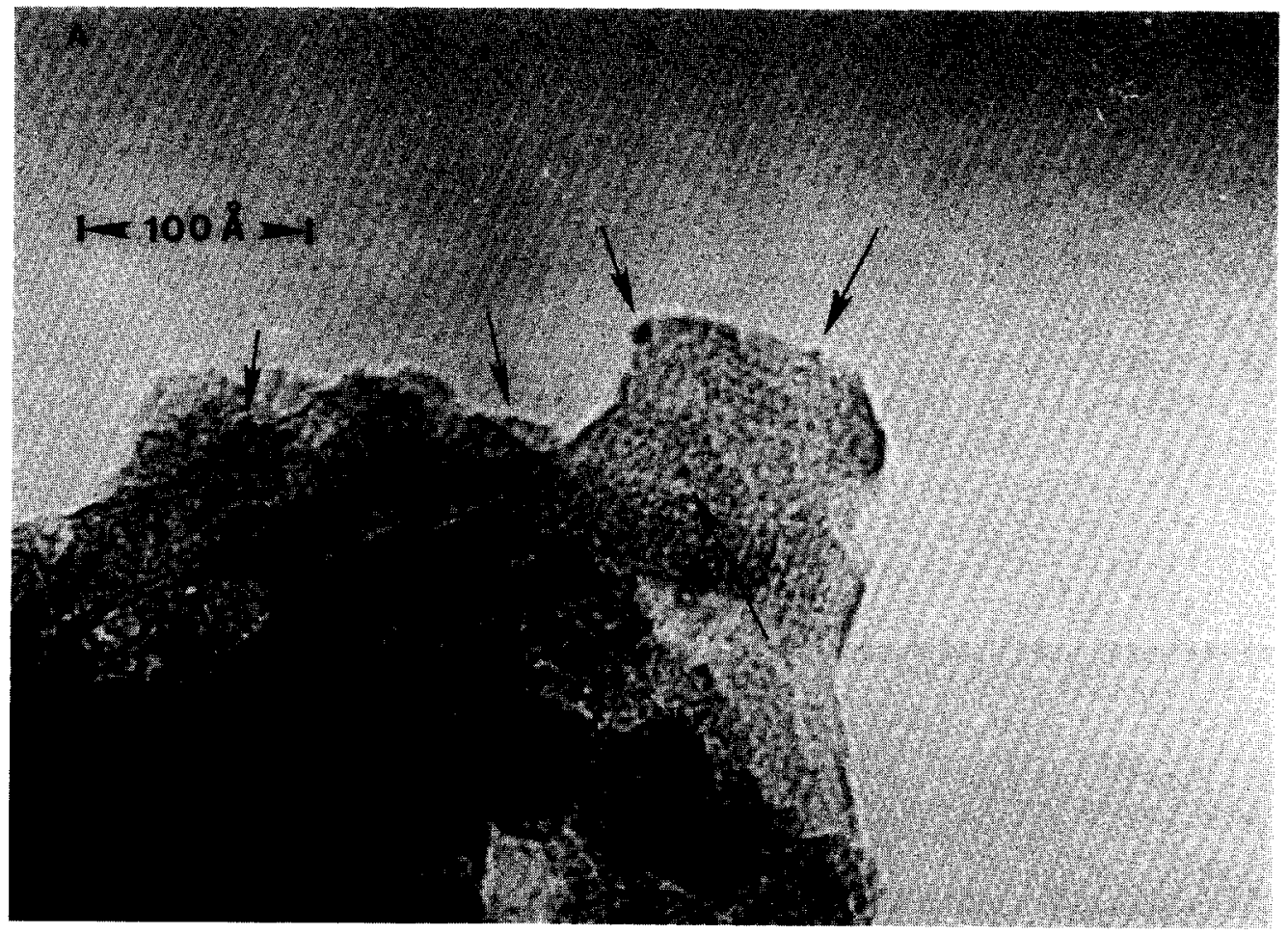

Fig. 6. Micrographs of a supported triosmium cluster sample after treatment in $\mathrm{H}_{2}$ at $400^{\circ} \mathrm{C}$. The same area was photographed in the sequence $(A)-(C)$ at approximately 5 -min intervals. The magnification is $525,000: 1$. 

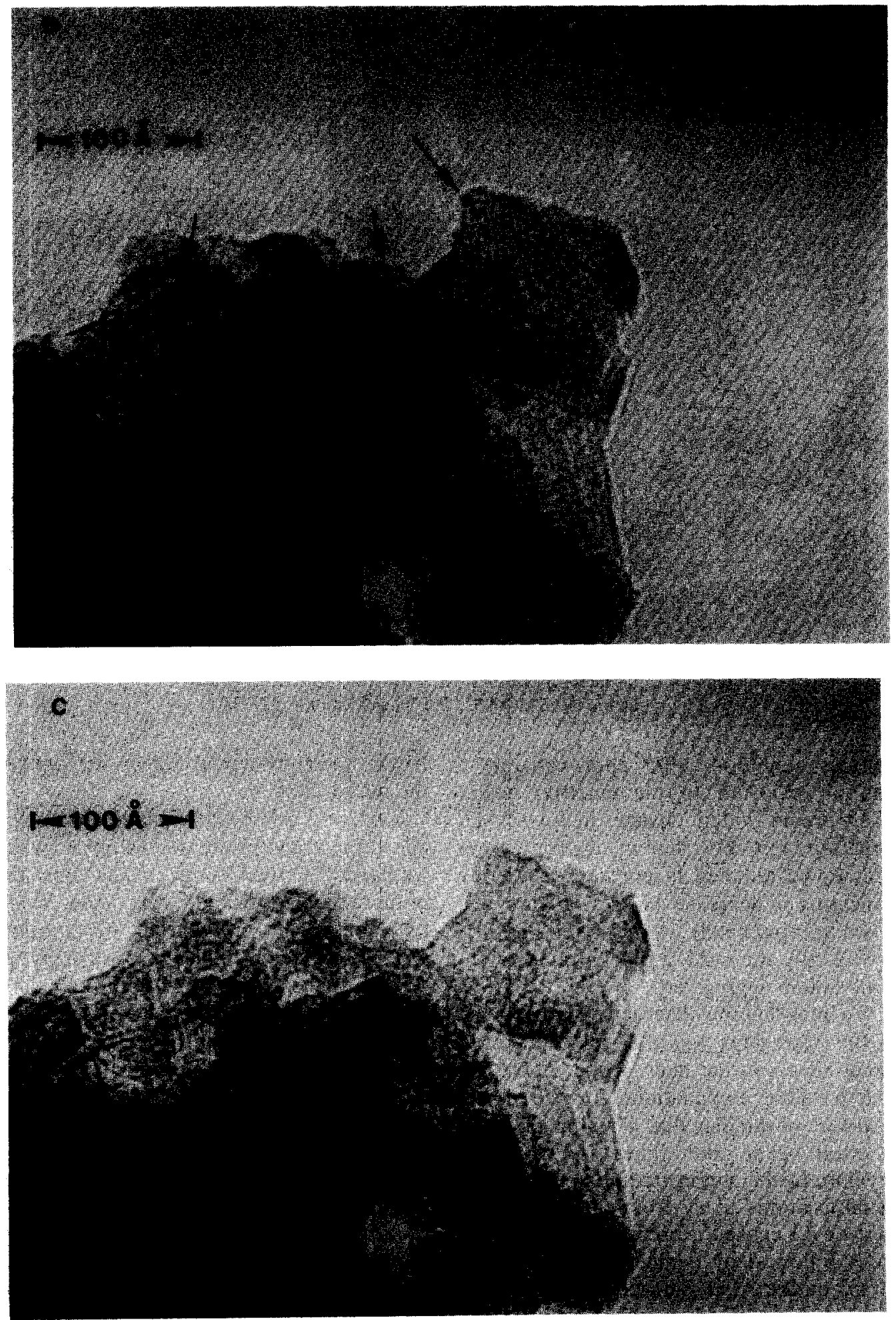

Fig. 6-Continued. 


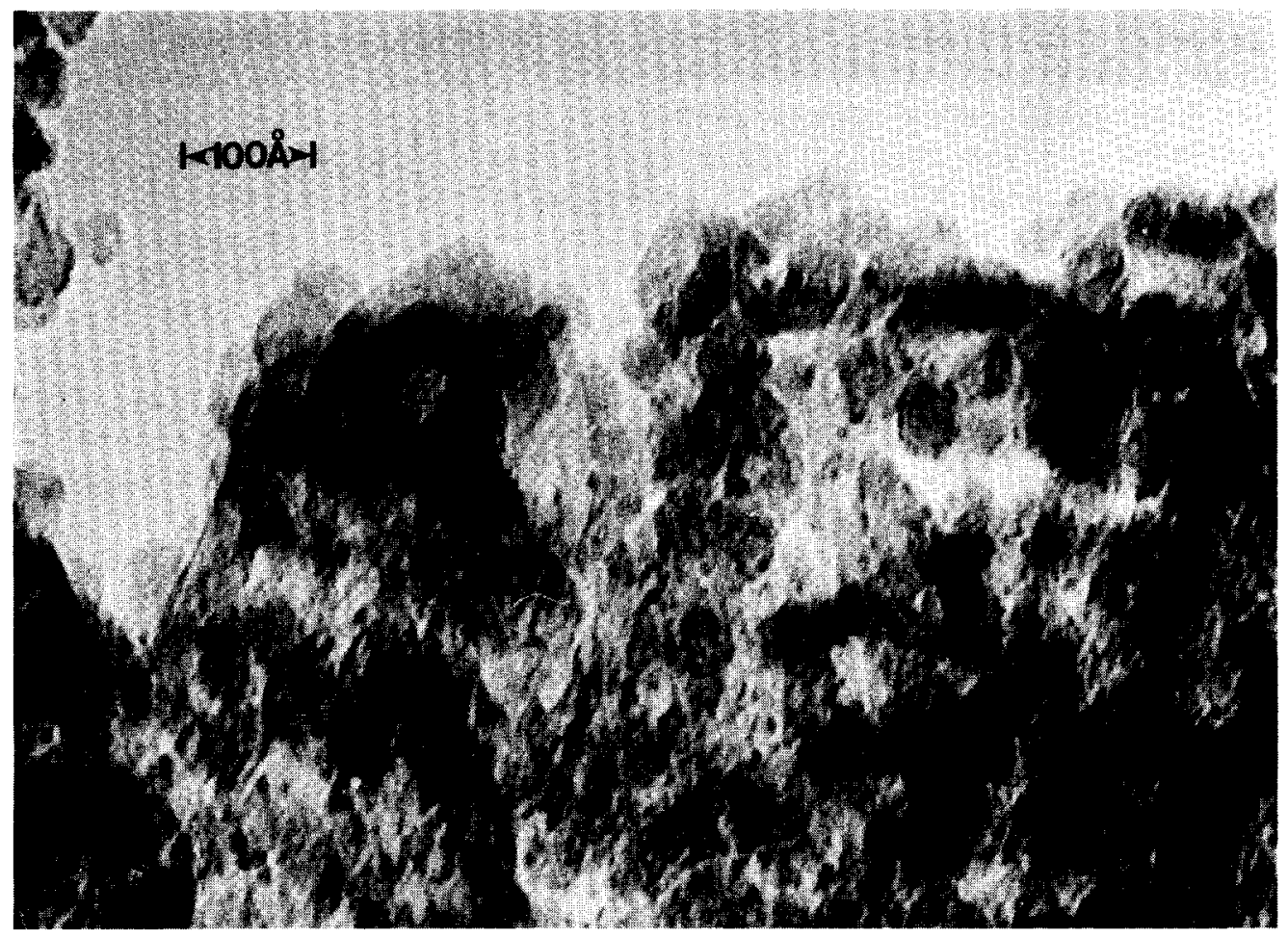

FIG. 7. Micrograph of osmium crystallites on $\gamma-\mathrm{Al}_{2} \mathrm{O}_{3}$, prepared by aqueous impregnation of $\left[\mathrm{H}_{2} \mathrm{OsCl}_{6}\right]$ followed by reduction in $\mathrm{H}_{2}$ at $400^{\circ} \mathrm{C}$. The magnification is $325,000: 1$.

defocus condition, after approximately 5 min of exposure to the electron beam. There are no evident changes in the $\gamma-\mathrm{Al}_{2} \mathrm{O}_{3}$ structure, but the osmium aggregates appear to be reduced in contrast, evidently indicating a decrease in size. Figure $6 \mathrm{C}$, taken approximately $15 \mathrm{~min}$ after Fig. 6A, shows only the $\gamma-\mathrm{Al}_{2} \mathrm{O}_{3}$ background, without osmium aggregates.

We infer that the observed disappearance of the aggregates was a result of electron beam effects in the microscope. There are two possible explanations for the disappearance of the osmium. The impact of the electron beam could have (1) caused a breakup of the aggregate and sputtering of osmium atoms away from the $\mathrm{Al}_{2} \mathrm{O}_{3}$ support or (2) caused a breakup of the aggregates followed by a migration of osmium atoms on the $\mathrm{Al}_{2} \mathrm{O}_{3}$ surface. Contrast from single osmium atoms would probably be obscured by the lattice structure of the $\gamma$ -
$\mathrm{Al}_{2} \mathrm{O}_{3}$, and they would not be detected by the microscopy.

Evidently this beam damage did not occur in the argon-pretreated samples, which we have described as ensembles consisting of three divalent osmium carbonyls. We infer, consistent with earlier observations (7), that the ensembles are strongly attached to the oxide support through ionic bonds and therefore stable in the high-intensity electron beam. The reduced osmium aggregates, in contrast, are less tightly held to the surface. We suggest that the osmium in these aggregates was zero valent and interacted much less strongly with the polar ions of the support than did the Os(II) ions. These suggestions are in accord with models accounting for transport of metal atoms on supports (15-17).

In contrast to the instability of the osmium aggregates formed by reduction of the cluster-derived osmium in hydrogen, 
the osmium crystallites, which were prepared by aqueous impregnation of $\gamma-\mathrm{Al}_{2} \mathrm{O}_{3}$ with $\left[\mathrm{H}_{2} \mathrm{OsCl}_{6}\right]$ followed by reduction in hydrogen at $400^{\circ} \mathrm{C}$, were stable; they did not disintegrate detectably under the impact of the electron beam (Fig. 7). In this case, the metal crystallites are larger (10 to $20 \AA$ in diameter) and contain many more atoms than the triosmium ensembles. Such threedimensional crystallites are expected to be more stable and less susceptible to breakup than the raft-like, "two-dimensional" groupings of osmium atoms in the aggregates.

\section{ACKNOWLEDGMENTS}

This work was supported by the National Science Foundation.

\section{REFERENCES}

1. Gates, B. C., and Lieto, J., CHEMTECH 195, 248 (1980).

2. Barth, R., Gates, B. C., Zhao, Y., Knözinger, H., and Hulse, J., J. Catal. 82, 147 (1983).

3. Li, X.-J., and Gates, B. C., J. Catal. 84, 55 (1983).

4. Deeba, M., Scott, J. P., Barth, R., and Gates, B. C., J. Catal. 71, 373 (1981).
5. Psaro, R., Ugo, R., Zanderighi, G. M., Besson, B., Smith, A. K., and Basset, J. M., J. Organometal. Chem. 213, 215 (1981).

6. Watson, P. L., and Schrader, G. L., J. Mol. Catal. 9, 129 (1980).

7. Deeba, M., and Gates, B. C., J. Catal. 67, 303 (1981).

8. Knözinger, H., and Zhao, Y., J. Catal. 71, 337 (1981).

9. Knözinger, H., Zhao, Y., Tesche, B., Barth, R., Epstein, R., Gates, B. C., and Scott, J. P., Faraday Discuss. Chem. Soc. 72, 54 (1982).

10. Deeba, M., Streusand, B. J., Schrader, G. L., and Gates, B. C., J. Catal. 69, 218 (1981).

11. Uh, Y. S., Weber, R. S., and Gates, B. C., in press.

12. Flynn, P. C., Wanke, S. E., and Turner, P. S., J. Catal. 33, 233 (1974).

13. Spence, J. C. H., "Experimental High Resolution Electron Microscopy," pp. 269 ff., Oxford Univ. Press, Oxford, 1981.

14. Spence, J. C. H., "Experimental High Resolution Electron Microscopy," Chapter 6. Oxford Univ. Press, Oxford, 1981.

15. Flynn, P. G., and Wanke, S. E., J. Catal. 34, 390 (1974).

16. Flynn, P. G., and Wanke, S. E., J. Catal. 34, 400 (1974).

17. Ruckenstein, E., and Dadyburjor, D. B., Rev. Chem. Eng. 1 (1983), in press. 